GU J Sci, Part C, 5(3): 247-254 (2017)

Gazi Üniversitesi
Fen Bilimleri Dergisi
PART C: TASARIM VE TEKNOLOJI
dergipark.gov.tr/http-gujsc-gazi-edu-tr

\title{
Alaşımsız Çelik Ve Östenitik Paslanmaz Çelik Levhaların Patlama Kaynağında Patlayıcı Oranının Arayüzey Oluşumuna Etkisi
}

\author{
Mehmet Serkan YILDIRIM ${ }^{1, *}$, Ahmet DURGUTLU ${ }^{2}$ \\ ${ }^{1}$ Gazi Üniversitesi, Teknik Bilimler MYO, Makina ve Metal Teknolojileri Böl. Ankara, Türkiye \\ ${ }^{2}$ Gazi Üniversitesi, Teknoloji Fakültesi, Metalurji ve Malz. Müh. Böl. Ankara, Türkiye
}

\begin{abstract}
Özet
Makale Bilgisi

Başvuru: 26/01/2017

Düzeltme: 15/06/2017

Kabul: 14/09/2017

Anahtar Kelimeler

Bu çalışmada, Dkp sac levha ve östenitik paslanmaz çelik levhaların farklı oranlarda patlayıcı (Elbar 5) miktarları kullanılarak paralel levha patlama kaynak yöntemi ile kaynaklanabilirliği ve patlayıcı oranının ara yüzey özelliklerine etkisi araştırılmıştır. Deneysel çalışmalar sonunda, patlama kaynağıyla DKP sac levha ve östenitik paslanmaz çelik malzemelerin birleştirilebildiği ve üst parça ağırlığına göre patlayıcı oranı arttı̆̆ında ara yüzeyin, doğrusal bir birleşme ara yüzeyinden dalgalı bir hale dönüştüğü görülmüştür. Patlayıcı oranının artışıla beraber oluşan dalgaların, boylarında ve genliklerinde bir artış olduğu, ayrıca çarpışmadan kaynaklanan soğuk deformasyondan dolayı, ara yüzeye yakın bölgelerin ve levhaların dış yüzeylerinin sertliklerinde bir artışın meydana geldiği tespit edilmiştir.
\end{abstract}

\section{Patlama}

Kaynağı/kaplama,

Paslanmaz çelik,

Patlayıcı Oranı,

Arayüzey

Keywords

\section{Explosive}

Welding/bonding

Stainless steel,

Explosive Ratio,

Interface

\section{The Effect of Explosive Ratio on Interface Formation in Explosion Weldıng of Non Alloyed and Austenitic Steel Plates}

\begin{abstract}
In this study, weldability of austenitic stainless steel sheet to DKP sheet metals by explosive welding and the effect of explosive ratio (Elbar 5) on the joint interface have been investigated experimentally. Experimental results show that austenitic stainless steel can be bonded to DKP sheet by using explosive bonding. The joint interface was transformed from line ar to wavy appearance within increasing explosive ratio with respect to upper plate weight. Moreover, with increasing explosive ratio, the wavelength and amplitude of waviness increased. Hardness measure indicate that the impact force leads to increase in hardness of the zone next to interface and outer surface of the plates.
\end{abstract}

\section{GİRIŞ (INTRODUCTION)}

Patlama kaynağı, geleneksel kaynak yöntemleriyle kaynatılamayan birbirinin aynı veya birbirinden farklı iki metal arasında patlayıcı ile elde edilen yüksek basınç yardımıyla yüksek hızda eğimli çarpışma sonucu meydana gelen birleştirme işlemidir. Şekil 1'de patlama kaynağ şematik olarak gösterilmiştir. Patlamalı kaynak yönteminde iki parça arasında metalurjik bağ oluşurken ara yüzeyde ya hiç ergime olmaz ya da çok az ergime meydana gelir [1-4]. Eğimli çarpışma, metal yüzeylerinden bir tabakanın metal jeti şeklinde, uzaklaşmasına neden olur. Çarpışma esnasında yüzeyden metal jeti şeklinde fişkıran bu tabakanın kalınlığı genellikle $0,05 \mathrm{~mm}$ 'den daha azdır. Bu metal jeti dışarı atılırken aynı zamanda çarpışan metal yüzeyinin temizliğini de gerçekleştirir. Metal yüzeyinde bulunan oksit, yă̆, gibi kaynak için zararlı etkiler oluşan jet ile birlikte dışarı atılmaktadırlar [5,6]. 


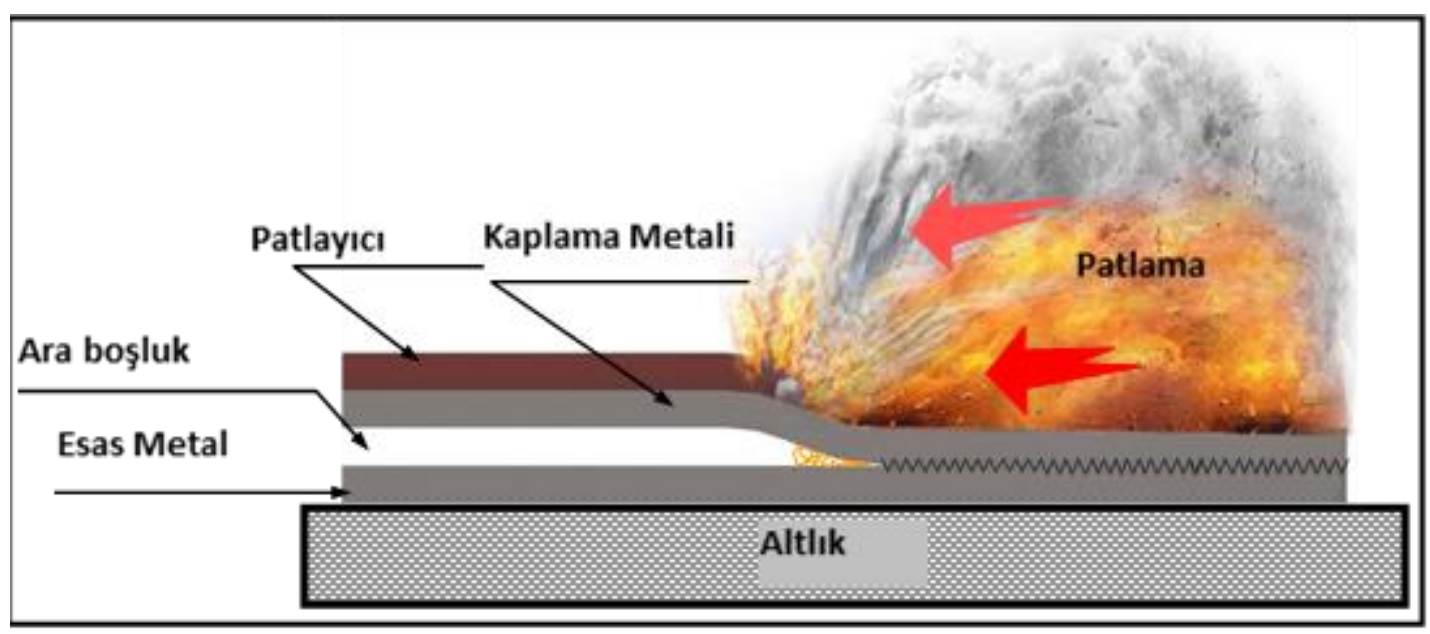

Şekil 1. Patlama kaynak yönteminin şematik gösterimi (schematic illustration of explosive welding method)

Patlama kaynağı işleminde üç temel eleman vardır. Bunlar; taban malzemesi, üst parça ve patlayıcıdır. Patlama kaynak işlemi temel geometrik şekilleri Şekil 2'de verilmiştir. Bu şekillerden de görüldüğü gibi taban malzemesi büyük bir altlık yardımıyla desteklenir. Bu kaynak yönteminde çoğu kez silindirik ve geniş düz yüzeylerin kaynaklı birleştirmeleri için paralel levha birleştirme geometrileri kullanılmaktadır. Paralel levha birleştirmelerinde, üst levhanın yeterince hızlanabilmesi için ara boşluk mesafesi en az, üst levhanın kalınlığının yarısından büyük olmalıdır [6-8]. Malzemenin kaplama sırasında bozulmaması için tampon tabaka ve patlayıcılar yerlerine aşağıdaki şekillerdeki gibi yerleştirilir.

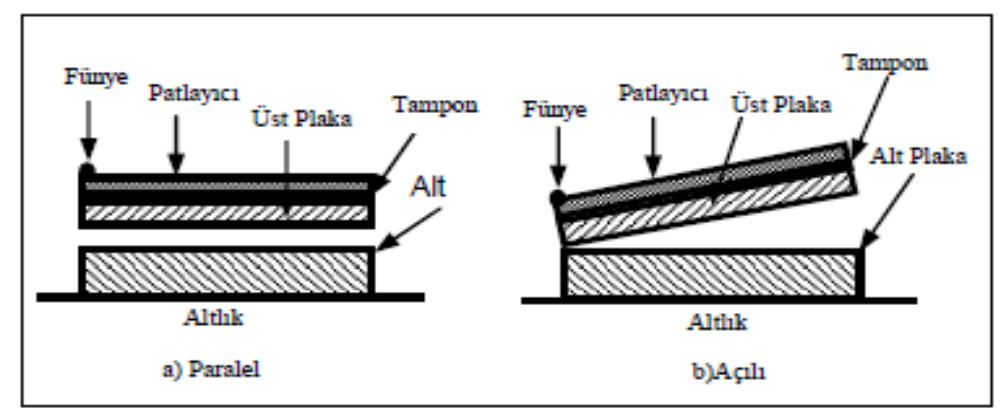

Şekil 2. Patlama kaynak işleminin temel geometrik şekilleri (Basic geometric figures of explosive welding process)

Patlama işlemi gerçekleştikten sonra temiz metal yüzeyleri, patlayıcı tarafindan oluşturulan yüksek basınç altında sıkıştırılır. İki malzemenin atomlarının toplam enerjisi birbirine yaklaştıkça azalır ve bir çekici veya bağlayıcı kuvvet ortaya çıkar, bu yüzden malzemeler arasında atomik boyutta bir birleşme meydana gelir. Bu birleşme tüm ara yüzey boyunca ilk çarpışma noktasından itibaren ilerler ve malzemelerde birleşme gerçekleşmiş olur [9].

Patlama kaynak yöntemi ısının yokluğu nedeniyle ergitme kaynağı, lehimleme veya sıcak haddeleme işlemlerindeki metalurjik karakteristiklerin çoğunu göstermez. Bu kaynak yöntemi, aynı özellikteki iki ya da daha fazla metali birleştirmek için kullanılabilir olmasına rağmen en büyük ticari potansiyeli, korozyon dayanımının amaçlandığı kaplamalı metallerin birleştirilmesi için kullanılabilir olmasıdır [10].

Şekil.3'de gösterildiği gibi her kaynak yönteminde olan birleştirmeye etki eden kaynak parametreleri patlama kaynak yönteminde de vardır. Bunlar; ara boşluk mesafesi (s), eğimli düzenlemelerde başlangıç açısı (paralel düzenlemeler için bu değer $\alpha=0$ dır) $(\alpha)$, patlayıcı oranı (patlayıcı kütlesinin üst levha kütlesine oranı) (R), patlayıcının patlama hızı (Vd), üst levhanın çarpma hızı (Vp), çarpışma açısı (Q), kaynak hızı (çarpışma noktası hızı) (Vc) ve altlık olarak sıralanabilir [11,12]. Şekil 3'de patlamalı kaynak işlemi parametreleri şematik olarak gösterilmiştir. 


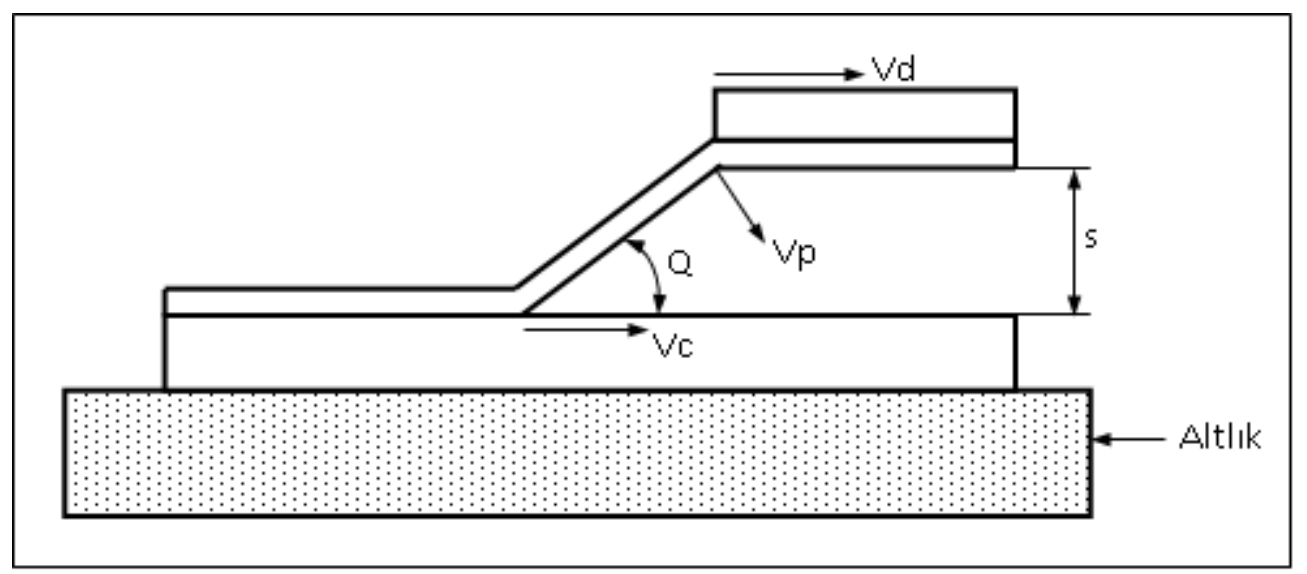

Şekil 3. Patlama kaynă̆ işlemi parametrelerinin şematik gösterimi (Schematic illustration of explosive welding process parameters)

Patlama kaynak işlemi parametrelerinden olan patlayıcı oranının (R), birleştirme ara yüzeyine olan etkisi oldukça fazladır. Patlayıcı oranının az veya çok olmasıyla beraber, oluşması muhtemel olan dalgalı arayüzeyin dalgalarının şekil ve boyutlarında önemli oranda değişmeler meydana gelmektedir. $\mathrm{Bu}$ değişime paralel olarak birleşme arayüzey alanı ve ara yüzeydeki soğuk deformasyon miktarı etkilenmektedir. Bu çalışmada, ticari olarak korozyon dayanımının amaçlandığı durumlarda kullanılmak üzere DKP sac levhalar ile Östenitik paslanmaz çelik levhalar farklı oranlarda patlayıcı miktarı kullanılarak birleştirilmiş ve arayüzey özellikleri incelenmiştir.

\section{MALZEME VE METOD (MATERIAL AND METHOD)}

Deneysel çalışmada patlayıcı oranının birleşme arayüzeyine etkisini görmek amacıyla 250x150x1 mm boyutlarında DKP sac ve östenitik paslanmaz çelik malzemeler paralel geometri kullanılarak patlatma kaynağı ile birleştirilmişlerdir. Kullanılan DKP sac levhanın ve östenitik paslanmaz çeliğin kimyasal bileşimi Tablo 1 ve Tablo 2'de verilmiştir.

Tablo 1. DKP sac malzemenin kimyasal kompozisyonu (Chemical composition of Dkp sheet material)

\begin{tabular}{|c|c|c|c|c|c|c|}
\hline Element & $\mathrm{Fe}$ & $\mathrm{C}$ & $\mathrm{Mn}$ & $\mathrm{P}$ & $\mathrm{S}$ & $\mathrm{Cu}$ \\
\hline \% A ğırlık & 98.12 & 0.19 & 1.5 & 0.04 & 0.04 & 0.6 \\
\hline
\end{tabular}

Tablo 2. Östenitik paslanmaz çeliğin kimyasal kompozisyonu (Chemical composition of austenitic stainless steel)

\begin{tabular}{|c|c|c|c|c|c|c|}
\hline Element & $\mathrm{Fe}$ & $\mathrm{C}$ & $\mathrm{Cr}$ & $\mathrm{Ni}$ & $\mathrm{Mo}$ & Diğer \\
\hline \% Ăğırlık & 68.1 & 0.02 & 17 & 11.7 & 2.7 & -- \\
\hline
\end{tabular}

Birleştirme işlemleri esnasında patlayıcı olarak M.K.E. Barutsan A.Ş’nin üretmiş̧ olduğu, en az $3500 \mathrm{~m} / \mathrm{s}$ patlama hızında ve bileşimi \% 92 Amonyum Nitrat, \% 5 Motorin ve \% 3 TNT olan Elbar-5 toz patlayıcıs1 kullanılmıştır. Deneylerde üst parça olarak DKP sac levha kullanılmış olup patlayıcı miktarı, bu levhanın ağırlığıyla orantılı olarak belirlenmiştir. Tablo 3'de deneylerde kullanılan patlayıcı oranı (R) ve miktarı verilmiştir. 
Tablo 3. Deneysel çalışmalarda kullanılan patlayıcı oran ve miktarları (Ratio and quantity of explosive which are used in experimantal study)

\begin{tabular}{|l|l|l|}
\hline Parça numarası & $\begin{array}{l}\text { Patlayıcı oranı } \\
(\mathbf{R})\end{array}$ & $\begin{array}{l}\text { Patlayıcı miktarı } \\
(\mathbf{m} \mathbf{x} \text { R)g }\end{array}$ \\
\hline 1 & 1,2 & 360 \\
\hline 2 & 1,5 & 450 \\
\hline 3 & 2 & 600 \\
\hline
\end{tabular}

Deneylerde ara boşluk mesafesi (s), üst parçanın kalınlığının iki katı olarak $2 \mathrm{~mm}$ alınmış olup, altık olarak da 1500x2000x150 mm ölçülerinde çelik tabla kullanılmıştır. Birleştirme işlemi esnasında levhaların altlığın akustik özelliğinden zarar görüp ayrılmasını ve firlatmayı engellemek amacıyla alt levha ile altlık arasında $5 \mathrm{~mm}$ kalınlığında plastik bir tabaka kullanılmıştır.

Patlama kaynağı yöntemi ile elde edilen birleştirmelerden, farklı patlayıcı oranı kullanılması sonucu birleşme arayüzeyinde oluşması muhtemel olan dalgalanmayı tespit etmek amacıyla incelenecek yüzeylerden patlama yönüne paralel olacak şekilde, mikroyapı numuneleri hazırlanmıştır. Hazırlanan numunelerin incelenecek olan yüzeyleri $\mathrm{SiC}$ su zımparalarıyla zımparalanıp, parlatma cihazında $3 \mu \mathrm{m}$ 'luk elmas pasta kullanılarak parlatılmıştır. Hazırlanan mikroyapı numuneleri $20 \mathrm{ml} \mathrm{HCL}, 4 \mathrm{~g} \mathrm{CuSO}_{4}$ ve $20 \mathrm{ml}$ su bileşiminden oluşan dağlama solüsyonuyla dağlanmıştır. Yine aynı numunelerde, arayüzeyden itibaren dışa doğru soğuk deformasyondan dolayı oluşan sertlik değişimini tespit etmek amaciyla östenitik paslanmaz çelik ve DKP sac malzemelerin farklı noktalarından Vickers sertlik ölçme metoduyla 300g yük kullanılarak sertlik değerleri alınmıştır.

\section{DENEY SONUÇLARI ve TARTIŞMA (EXPERIMENTAL RESULTS and DISCUSSION)}

\subsection{Mikroyapı Sonuçları (Microstructure Results)}

Patlama kaynağı yöntemi ile değişik patlayıcı oranlarında birleştirilmiş DKP sac-östenitik paslanmaz çelik birleştirmelerinden elde edilen optik mikroskop görüntüleri şekil 4 a-b-c'de sırasıyla verilmiştir. Buradaki görüntülerin tümünde östenitik paslanmaz çelik malzemeler üst levha, DKP sac malzemeler ise alt levha olarak görülmektedir.

Şekil 4 a'daki mikroyapı fotoğrafından görüldüğü gibi patlayıcı oranının en az olduğu $(R=1,2)$ birleştirme numunesinde birleşme arayüzeyinde bir dalgalanma meydana gelmiştir. Patlayıcı oranının $R=1,5$ olduğu Şekil 4 b'de ise patlayıcı oranının artmasıyla beraber birleşme arayüzeyinde oluşan dalga boyunda az da olsa bir artış dikkat çekmektedir. Patlayıcı oranının en fazla olduğu Şekil 4 c'de görülen birleşme arayüzeyinde ise oluşan dalga boylarında ve genliklerindeki artış belirgin bir şekilde kendini göstermektedir.

Patlayıcı oranının en yüksek olduğu malzemede dalga boyu 900-950 $\mu \mathrm{m}$ arasında ölçülürken dalga genliği 420-450 $\mu \mathrm{m}$ arasında ölçülmüştür. Deneysel çalışmalarda kullanılan en düşük patlayıcı oranıda $(\mathrm{R}=1,2)$ bile birleştirilen malzemelerin arayüzeylerinde patlama kaynağının tipik arayüzeyi olan dalgalanma meydana gelmiştir. Bundan önce yapılan çalışmalarda[13], patlama kaynağında kullanılan patlayıcı miktarının hem dalga boyunu hem de genliğini etkilediğii, ara boşluk mesafesinin ise daha çok dalga genliğinde etkili olduğu belirtilmiştir. Yapılan deneysel çalışmada ara boşluk mesafesi sabit seçildiğinden dolayı dalga boylarındaki artışa rağmen genliklerinin fazla artmaması normal bir sonuç olarak değerlendirilmekte ve daha önce yapılan araştırmalar ile paralellik arz etmektedir. 

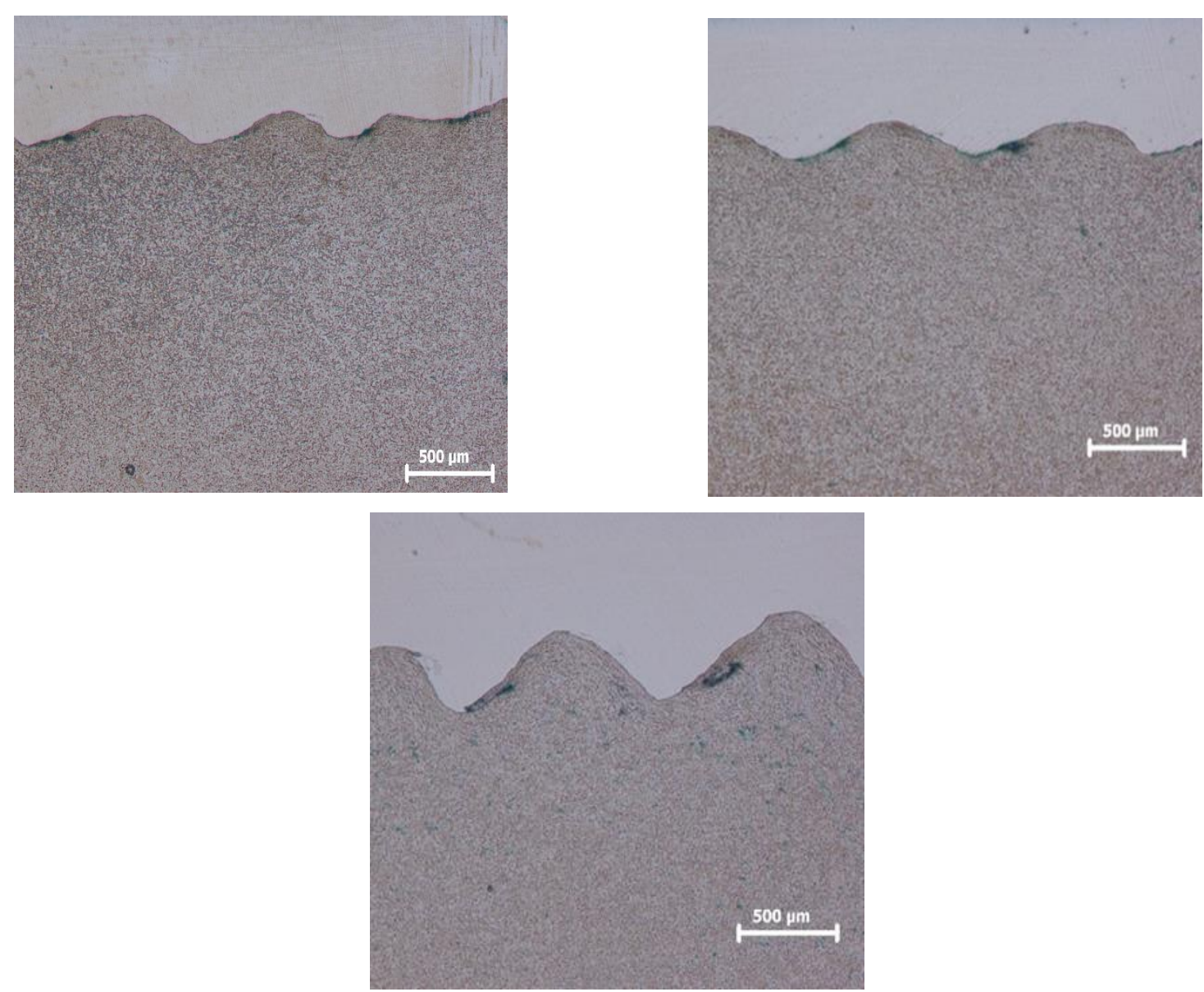

Şekil 4. DKP sac-östenitik paslanmaz çelik birleştirmelerinin optik mikroskop görüntüleri (Microscopical image of DKP sheet austenitic stainless steel joints) a) $R=1,2 b$ ) $R=1,5$ c) $R=2$

Deneysel çalışmalar sonucu çok yüksek büyütme oranlarında birleşme arayüzeyi incelemelerinde, patlayıcı oranlarının düşük olduğu birleştirmelerde arayüzeye yakın bölgedeki tanelerde çok az bir deformasyon olduğu, patlayıcı oranının yüksek olduğu birleştirmelerde ise bu deformasyon miktarının önemli derecede arttığı görülmektedir. Burada birleşme esnasında malzemelere uygulanan basıncın etkisiyle arayüzeye yakın bölgedeki tanelerin uzadığı ve arayüzeyden uzaklaştıkça bu değişimin azaldığı mikroskop altında görülebilmektedir.

\subsection{Sertlik Sonuçları (Hardness Results)}

Patlama kaynağı yöntemi ile değişik patlayıcı oranlarında birleştirilmiş DKP sac-östenitik paslanmaz çelik birleştirmelerinin birleşme ara yüzeylerindeki sertlik değişimlerini görmek amacıyla 300 g yük kullanılarak Vickers yöntemiyle mikrosertlik değerleri ölçülmüştür. Sertlik ölçümleri birleşme ara yüzeyinden itibaren her malzeme çiftinde 100, 500 ve $900 \mu \mathrm{m}$ mesafelerden alınmıştır. Farklı patlayıcı oranına sahip birleştirmelerden elde edilen sertlik değerleri aşağıda Tablo 4'te verilmiştir 
Tablo 4. DKP sac-östenitik paslanmaz çelik levha ve metal çiftleri sertlik değerleri (Hardness value of DKP sheet austenitic stainless steel plate and metal pairs)

\begin{tabular}{|c|c|c|c|c|c|}
\hline \multirow{3}{*}{$\underset{\text { No }}{\text { Numune }}$} & \multirow{3}{*}{ Malzemeler } & \multirow{3}{*}{$\begin{array}{c}\text { Levha } \\
\text { Sertliği } \\
\text { (HV) }\end{array}$} & \multirow{2}{*}{\multicolumn{3}{|c|}{$\begin{array}{l}\text { Metal Çifti Sertliği(HV300g) } \\
\text { Ara Yüzeyden Uzaklık ( } \mu \mathrm{m})\end{array}$}} \\
\hline & & & & & \\
\hline & & & 100 & 500 & 900 \\
\hline \multirow[t]{2}{*}{$(\mathrm{R}=1,2)$} & $\begin{array}{l}\text { Ö.Paslanmaz } \\
\text { çelik }\end{array}$ & 330 & 337 & 330 & 336 \\
\hline & DKP sac & 180 & 190 & 182 & 188 \\
\hline \multirow[t]{2}{*}{$(\mathrm{R}=1,5)$} & $\begin{array}{l}\text { Ö.Paslanmaz } \\
\text { çelik }\end{array}$ & 330 & 340 & 332 & 340 \\
\hline & DKP sac & 180 & 195 & 183 & 193 \\
\hline \multirow[t]{2}{*}{$(\mathrm{R}=2)$} & $\begin{array}{l}\text { Ö.Paslanmaz } \\
\text { çelik }\end{array}$ & 330 & 349 & 332 & 348 \\
\hline & DKP sac & 180 & 198 & 183 & 198 \\
\hline
\end{tabular}

Yukarıda verilmiş olan tabloya bakıldığında patlayıcı oranının $\mathrm{R}=1,2$ olduğu numunede DKP sac levhanın sertliği $180 \mathrm{HV}$ olan ilk sertliğinden, birleşme ara yüzeyine en yakın bölgede $(100 \mu \mathrm{m})$ 190 HV değerine ulaştığı görülmektedir. DKP sac levhanın sertliği birleşme ara yüzeyine $500 \mu \mathrm{m}$ mesafede, yani yaklaşık olarak levha kalınlığının orta kısmında ilk sertliğine yakın bir değer gösterirken (182HV) birleşme ara yüzeyine $900 \mu \mathrm{m}$ mesafede yani dış yüzeyde $188 \mathrm{HV}$ değerine ulaşmıştır. Patlamalı kaynak işleminde levhaların çarpışarak kaynaklanmasından dolayı birleşme ara yüzeyinde bir deformasyon sertleşmesi gerçekleşmektedir. Bu sebepten dolayı birleşme ara yüzeyine yakın bölgelerde levhaların sertliğinde bir artış söz konusu olmaktadır. DKP sac levhanın orta kısmındaki sertlik değerinde önemli bir artış gözükmemektedir. Buradaki sertlik değeri levhanın ilk sertlik değeri olan $180 \mathrm{HV}$ değerine çok yakındır. Birleşme ara yüzeyinde oluşan deformasyon sertleşmesi levhanın orta kısmında etkili olamamıștır. DKP sac levhanın birleşme ara yüzeyinden yaklaşık olarak $900 \mu \mathrm{m}$ mesafe levhanın dış yüzeyine çok yakın olup buradaki sertliği ifade etmektedir. DKP sac levhanın dış yüzeyi kullanılan altlık ile temas halinde olup patlama esnasındaki basınçtan etkilenerek alt levha ile çarpışmasından dolayı burada da bir deformasyon sertleşmesi gerçekleşmiş ve sertlik değerinde bir artış görülmüştür. Yine aynı patlayıcı oranında östenitik paslanmaz çelik levhada ise sertlik $330 \mathrm{HV}$ olan ilk sertliğinden birleşme arayüzeyine $100 \mu \mathrm{m}$ mesafede $337 \mathrm{HV}$ değerine, $900 \mu \mathrm{m}$ mesafede (yaklaşık dış yüzey) $336 \mathrm{HV}$ değerine ulaşmıș ve levhanın orta kısmı ilk sertliğini muhafaza ederek $330 \mathrm{HV}$ değerinde kalmıştır. Östenitik paslanmaz çelik levhanın birleşme ara yüzeyi ve buraya yakın olan bölgedeki sertlik artışı çarpışma esnasındaki deformasyondan kaynaklanmaktadır. Dış yüzeydeki sertlik artışı ise patlayıcının patlaması esnasında oluşan şoktan dolayı meydana gelmektedir. Patlayıcı oranının $\mathrm{R}=1,5$ olduğu birleştirmede DKP sac levhanın sertliği ara yüzeye $100 \mu \mathrm{m}$ mesafede 195 $\mathrm{HV}, 500 \mu \mathrm{m}$ mesafede $183 \mathrm{HV}, 900 \mu \mathrm{m}$ mesafede $193 \mathrm{HV}$ olurken, östenitik paslanmaz çelik levhanın sertliği ara yüzeye $100 \mu \mathrm{m}$ mesafede $340 \mathrm{HV}, 500 \mu \mathrm{m}$ mesafede $332 \mathrm{HV}, 900 \mu \mathrm{m}$ mesafede $340 \mathrm{HV}$ değerlerinde olmuştur. Farklı patlayıcı oranlarında birleştirilen numunelerde patlayıcı oranının artması ile beraber birleştirilen levhaların sertlik değerlerinde de artmalar görülmüştür. Patlayıcı oranının en fazla olduğu $(\mathrm{R}=2)$ numunede ise Dkp sac levhada birleşme ara yüzeyine $100 \mu \mathrm{m}$ mesafede sertlik $198 \mathrm{HV}$ değerini bulurken levhanın orta kısmında ise sertlik değeri 183 HV olmuştur. Dış yüzeyde ise sertlik değeri 198 HV değerine ulaşmıştır. Aynı patlayıcı oranında östenitik paslanmaz çelik levhada ise birleşme ara yüzeyine $100 \mu \mathrm{m}$ mesafede sertlik değeri $349 \mathrm{HV}$ olurken $900 \mu \mathrm{m}$ mesafede bu değer $348 \mathrm{HV}$ değerine ulaşmıştır. Bu patlayıcı oranında da östenitik paslanmaz çelik levhanın orta kısmı 332 HV sertlik değerine ulaşarak yaklaşık ilk sertliğini muhafaza etmiştir. 


\section{SONUÇLAR (CONCLUSIONS)}

- Alışılmış kaynak yöntemleri ile sağlıklı bir şekilde birleştirilen östenitik paslanmaz çelik, ve DKP sac levhalar uygun parametreler kullanıldığı durumda MKE üretimi olan Elbar 5 kodlu toz patlayıcı kullanılarak patlamalı kaynak yöntemi ile de problemsiz bir şekilde birleştirilebilmektedirler.

- Patlayıcı oranının düşük olduğu birleştirmelerde üst levha yeterince hızlanamamış ve birleşme arayüzeyinde oluşan dalgalanmadaki boy ve genlikler düşük boyutlarda oluşmuştur.

- Patlamalı kaynak yönteminde kullanılan patlayıcı oranının artması ile yüksek çarpışma hızına ve basıncına ulaşıldığından elde edilen birleştirmelerin ara yüzeylerinde meydana gelen dalgaların boy ve genliklerinde belirgin oranda artış görülmektedir.

- Artan patlayıcı oranına bağlı olarak, birleştirilmiş levhaların özellikle birleşme ara yüzeyine yakın bölgeleri ve dış yüzeylerindeki sertlik değerlerinde yükssek hızdaki çarpışma nedeni ile oluşan deformasyondan dolayı artışlar meydana gelmektedir.

\section{KAYNAKLAR (REFERENCES)}

[1] Kaya Y. An investigation into the microstructure, mechanical and corrosion properties of grade a ship steel-stainless steel composites produced byexplosive welding method. Ph D. Thesis, Karabük University, TR, 2014.

[2] Gülenç, B. Kahraman ,N “'Modern kaynak teknolojisi kitapı', Ankara (2013)

[3] Durgutlu, A., "Patlama kaynağı yöntemi ile bakır-paslanmaz çelik malzemelerinin birleştirilmesi ve ara yüzeyin mekanik-mikroyapı özelliklerinin incelenmesi”, Doktora Tezi, Gazi Üniversitesi Fen Bilimleri Enstitüsü, Ankara, 1-111 (2003).

[4] Acarer, M., "Patlamalı Kaynakta Patlayıcı Oranı, Ara Boşluk Mesafesi ve Altlık Cinsinin Çelik/Çelik Birleştirilmesi Kalitesine Etkisi”, Doktora Tezi, Sakarya Üniversitesi, Fen Bilimleri Enstitüsü, Makine Eğitimi Anabilimdalı, Sakarya, 5-119 (2001).

[5] Acarer, M.,Gülenç, B., Fındık, F., "Patlamalı Kaynak İşlem Parametrelerinin Birleşme Arayüzeyine Etkisi” 8. Denizli Malzeme Sempozyumu, Pamukkale Üniversitesi, Mühendislik Fakültesi, Denizli, 166-171 (2000).

[6] Explosion welding, "Fundamentals of Process", WeldingHandbook, V 3: 264-277 (1992).

[7] Abe, A., "Numerical Study of The Mechanism of Wavy Interface Generation in Explosive Welding", JSME International Journal, 40 (3): 395-401 (1997).

[8] Blazynski, T.Z., "Explosive Welding, Forming and Compaction”, Elsevier Science Pub., Applied Science, NewYork, 402-404 (1983).

[9] Brasher, D.G.,Butter, D.J., "Explosive welding: principles and potentials", Advanced Materials\&Processes, 147 (3): (1995).

[10] Banker, J.G.,Edvard, G.R., “Explosion Welding” ASM Handbook, 6: 303-305 (1993).

[11] Vonne, D.L., "Procedure Development and Process Considerations for Explosion Welding",ASM Handbook, 6: 896-900 (1993). 
[12] Patterson, R.A., "Fundamentals of Explosion Welding”, ASM Handbook, 6: 160-164 (1993).

[13] Balasubramanian, V.,Rathinasabapathi, M., Raghukandan, K., "Modelling of Process Parameters in Explosive Cladding of Mild steel and Aluminium", Journal of Materials Processing Technology, 63: 83-88 (1997). 